NIST Technical Note 1989

\title{
NIST Interlaboratory Study of Aerosol Absorption Measurements using Photoacoustic Spectroscopy
}

Christopher D. Zangmeister James G. Radney

This publication is available free of charge from: https://doi.org/10.6028/NIST.TN.1989
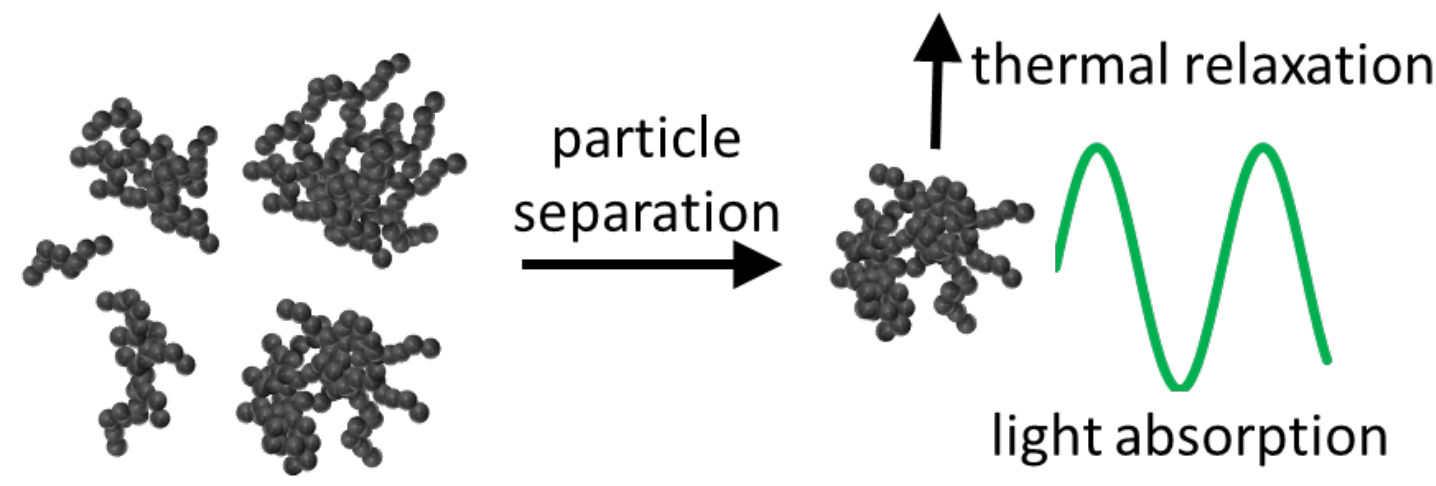

light absorption

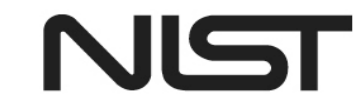

National Institute of Standards and Technology U.S. Department of Commerce 
(This page intentionally blank) 


\section{NIST Interlaboratory Study of Aerosol Absorption Measurements using Photoacoustic Spectroscopy}

Christopher D. Zangmeister

James G. Radney

Chemical Sciences Division

Material Measurement Laboratory

This publication is available free of charge from:

https://doi.org/10.6028/NIST.TN.1989

April 2018

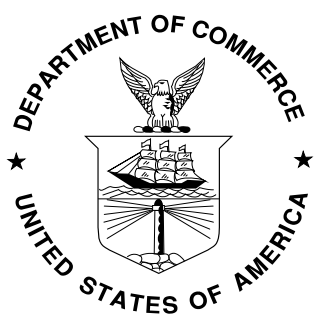

U.S. Department of Commerce Wilbur L. Ross, Jr., Secretary

National Institute of Standards and Technology Walter Copan, NIST Director and Undersecretary of Commerce for Standards and Technology 
National Institute of Standards and Technology Technical Note 1989

Natl. Inst. Stand. Technol. Tech. Note 1989, 29 pages (April 2018)

CODEN: NTNOEF

This publication is available free of charge from:

https://doi.org/10.6028/NIST.TN.1989 


\begin{abstract}
The National Institute of Standards and Technology coordinated an interlaboratory study for laboratories that use photoacoustic spectroscopy to measure and report aerosol absorption. This report describes the design and results for the NIST Interlaboratory Study of Aerosol Absorption Measurements using Photoacoustic Spectroscopy from twelve participating laboratories using a material that was characterized and distributed by NIST on June 12, 2017. Participants were requested to provide measurement results by August 30, 2017. The participating laboratories reported 4,569 aerosol absorption cross sections as a function of particle size, particle mass and wavelength. The results indicate that for laboratories with access to electrical mobility-only selection, measurements should be made for $D_{\mathrm{m}} \geq 400 \mathrm{~nm}$, where deviations of measured absorption cross-section are $\leq 10 \%$ of measurements made with electrical mobility and mass selection. The results also indicate that multiple wavelength measurements should be performed using a single photoacoustic cell to eliminate variation in measurement parameters, if possible.
\end{abstract}

\author{
Key words \\ Aerosol, absorption, photoacoustic spectroscopy, PAS
}

\begin{abstract}
Disclaimer
Certain commercial entities, equipment, or materials may be identified in this document in order to describe an experimental procedure or concept adequately. Such identification is not intended to imply recommendation or endorsement by the National Institute of Standards and Technology, nor is it intended to imply that the entities, materials, or equipment are necessarily the best available for the purpose.
\end{abstract}




\section{Table of Contents}

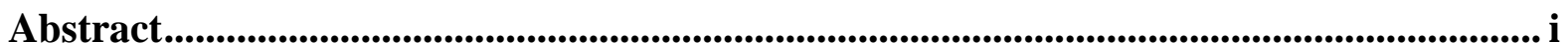

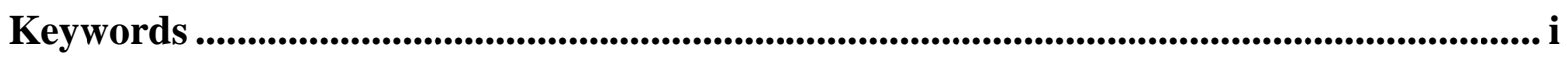

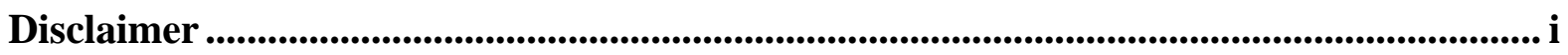

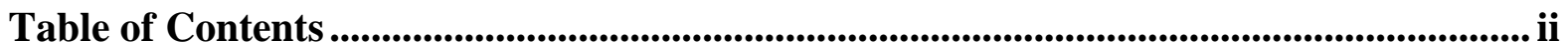

Definition of Terms ..................................................................................................................... iii

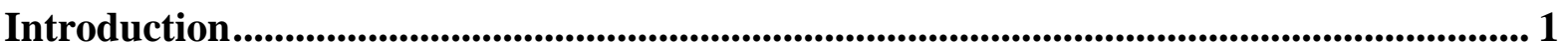

Interlaboratory Study: Measurement of Aerosol Absorption using Photoacoustic Spectroscopy ..................................................................................................................... 3

1. Aerosol Characterization and Selelction ..................................................................... 3

2. Measurement of $C B C_{A b s}$ for $D_{m} \& m_{p}$ selected aerosol ....................................... 6

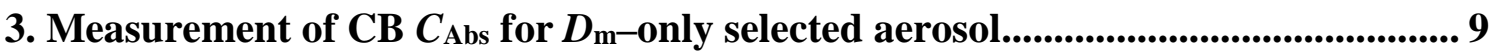

4. Comparison of $D_{\mathrm{m}}$ and $m_{\mathrm{p}}$ selelcted CB $C_{\mathrm{Abs}}$ measurements ................................ 11

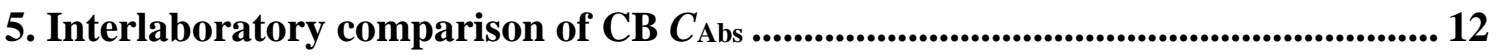

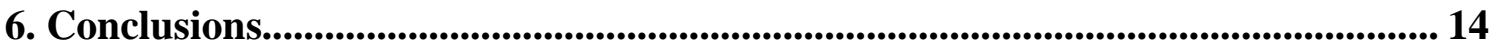

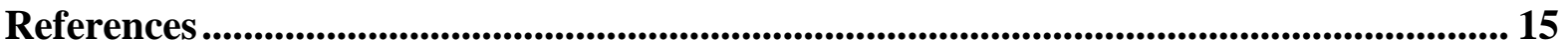

Appendix: Supplemental Materials............................................................................................ 17 


\section{Definition of variables, terms, and units used in this report}

$\mathrm{CB}=$ carbon black

$\mathrm{CPC}=$ condensation particle counter

DMA = differential mobility analyzer

$C_{\text {Abs }}=$ absorption cross-section $\left(\mathrm{m}^{2}\right)$

$C_{\text {Abs,Dm }}=$ absorption cross-section $\left(\mathrm{m}^{2}\right)$ of mobility selected aerosol

$C_{\mathrm{Abs}, \mathrm{Dm}} \& \mathrm{mp}=$ absorption cross-section $\left(\mathrm{m}^{2}\right)$ of mobility and mass selected aerosol

$\mathrm{CV}=$ coefficient of variation

$D_{\mathrm{f}}=$ mass-mobility scaling exponent

$D_{\mathrm{m}}=$ particle mobility diameter $(\mathrm{nm})$

$D_{\mathrm{m}} \& m_{\mathrm{p}}=$ selection by particle mobility and particle mass

$k_{0}=$ mass scaling prefactor $(\mathrm{g})$

$M A C=$ mass-specific absorption coefficient $\left(\mathrm{m}^{2} \mathrm{~g}^{-1}\right)$

$m_{\mathrm{p}}=$ particle mass $(\mathrm{g})$

$N=$ number of measurements

$P=$ particle number density per unit volume $\left(\# \mathrm{~cm}^{-3}\right)$

PAS = photoacoustic spectroscopy

$q=$ particle net charge

SP2 = single particle soot photometer

$Z_{\mathrm{p}}=$ electrical mobility $(\mathrm{nm})$

$\alpha_{\text {Abs }}=$ absorption coefficient $\left(\mathrm{m}^{-1}\right)$

$\lambda=$ wavelength $(\mathrm{nm})$

$\mu_{\text {geo }}=$ geometric mean aerosol diameter (nm)

$\sigma_{\text {geo }}=$ geometric standard deviation

$\gamma=$ drag slip correction

$\sigma=$ standard deviation

$\overline{\mathrm{x}}=$ average 


\section{Introduction}

Quantifying the amount of light absorbed by suspended nano- and micro-particles (aerosols) in the Earth's atmosphere allows a better understanding of their impact and role in energy distribution and balance. It is currently estimated that absorption of light by highly absorbing aerosol produced during the incomplete combustion of carbonaceous materials represents the second largest positive radiative forcing after $\mathrm{CO}_{2}[1]$.

In-situ measurements of aerosol light absorption are typically made using photoacoustic spectroscopy (PAS) where a microphone is used to detect the pressure wave generated from the thermal relaxation of light absorbed by a particle. Absorption coefficients, $\alpha_{\text {Abs, }}$, measured by the spectrometer are the quotient of the particle absorption cross-section $\left(C_{\mathrm{Abs}}\right)$ and the particle number density $(P)$, or $C_{\text {Abs }}=\alpha_{\text {Abs }} / P$; $P$ can be measured using a condensation particle counter (CPC) or other comparable technique. Aerosol $C_{\text {Abs }}$ are reported in units of $\mathrm{m}^{2}$ and most often as function of particle size (or mobility diameter, $D_{\mathrm{m}}$ ). Recent developments in the field of mass-based aerosol metrology have enabled particle selection and reporting as a function of particle mass $\left(m_{\mathrm{p}}\right)$ for aerosol that has also been $D_{\mathrm{m}}$ selected $[2,3]$.

The aerosol community recognizes the need for instrumental intercomparisons, but such comparisons have been limited by the lack of suitably characterized and transferrable nanomaterials that mimic the chemical and/or physical properties of materials observed in the atmosphere [4]. Thus, the field has focused its efforts on measurements of co-located instrumentation analyzing a common aerosol stream to: 1) gain a better understanding of the correlations between measurement techniques and 2) quantitatively compare similar instrument designs and methods [5-8].

This study describes the first intercomparison of laboratories reporting a measurand $\left(C_{\mathrm{Abs}}\right)$ in which: 1) the participants were not co-located, 2) all measurements were performed using a common method (PAS) and 3) a transferrable, aerosolizable, and well characterized nanomaterial was supplied to all the participating laboratories for use. The material was first characterized at the National Institute of Standards and Technology (NIST) and has a $C_{\text {Abs }}$ similar to highly absorbing carbonaceous aerosol observed in the atmosphere.

The participants in this NIST-coordinated study measured $C_{\text {Abs }}$ using photoacoustic spectroscopy and an appropriate particle counting method for aerosol classified by particle mobility only ( $D_{\mathrm{m}}$-only) or by particle mobility and particle mass $\left(D_{\mathrm{m}} \& m_{\mathrm{p}}\right)$. The material used to measure $C_{\mathrm{Abs}}$ was distributed by NIST to all participant for measurement. The goals of this study were two-fold:

- $\quad$ To determine interlaboratory variability of $C_{A b s}$ measurements of $D_{\mathrm{m}} \& m_{\mathrm{p}}$ selected aerosol, where $C_{\text {Abs }}$ is reported on a per mass basis.

- $\quad$ To determine interlaboratory variability of $C_{\text {Abs }}$ measurements of $D_{\text {m}}$-only selected aerosol, where $C_{\text {Abs }}$ is reported on a per particle mobility basis.

Potential contributors to the intercomparison were identified by their publication record in peer-reviewed literature and were invited to participate (See "Letter Describing Intercomparison to Potential Contributors” in the Appendix). All participants measured 
aerosol $C_{\mathrm{Abs}}$ using their self-identified best practice methods involving a photoacoustic spectrometer and a suitable particle counting technique for aerosol that was selected by $D_{\mathrm{m}}$ - only and/or $D_{\mathrm{m}} \& m_{\mathrm{p}}$. The methods used for aerosol selection were determined by the instrumentation available to each participating laboratory (see "Cover Letter Distributed to Participants" in the Appendix). The data was reported as a function of $D_{\mathrm{m}}$, wavelength $(\lambda)$, and $m_{\mathrm{p}}$, if available. Participants reported their data to NIST, using a standardized reporting template, where it was compiled, evaluated for consensus values, and summarized using results from all laboratories. An anonymized report was distributed to each participating laboratory at the end of the intercomparison (see "Report to Participants" in the Appendix). 


\section{Interlaboratory Study: Measurement of Aerosol Absorption using Photoacoustic Spectroscopy}

\section{Aerosol characterization and selection}

The $C_{\mathrm{Abs}}$ of $D_{\mathrm{m}}$-only and $D_{\mathrm{m}} \& m_{\mathrm{p}}$ selected aerosolized water-soluble carbon black (CB, Cabo-Jet 200, Cabot Corporation, Billerica, MA) was measured. The spectral properties of CB closely mimic materials observed from the incomplete combustion of carbonaceous fuels with $C_{\mathrm{Abs}} \propto \lambda^{-1}[9,10]$.

Individual units of aqueous CB were distributed to participants in $0.42 \mathrm{~mL}$ aliquots at a mass concentration of $(21.73 \pm 0.04) \mathrm{g}$ of solid material per $100 \mathrm{~g}$ of sample. Three vials were distributed to each participating laboratory to ensure sufficient material was available for analysis. Participants were instructed to dilute the aliquots to $100 \mathrm{~mL}$ using distilled water to form the aqueous suspension that would be used for analysis. Each laboratory atomized the prepared solution to form a CB aerosol that produced particles with $\left(30<D_{\mathrm{m}}<700\right) \mathrm{nm}$, see Fig. 1a. The particle mobility diameter is approximately log-normally distributed, therefore the mean $\log \left(D_{\mathrm{m}}\right)$ is the geometric mean of $D_{\mathrm{m}}$ defined here as $\mu_{\text {geo }}(\mathrm{nm})$ and the geometric standard deviation $\left(\sigma_{\text {geo }}\right)$. The aerosol distribution varied between laboratories and could be divided into two groupings based on reported $\mu_{\text {geo }}$ shown in Table 1 . Of the 11 laboratories that reported mobility data, three laboratories had a mean $\mu_{\text {geo }}$ of $99.0 \pm 5.2(1 \sigma) \mathrm{nm}$ and a geometric standard deviation $\left(\sigma_{\text {geo }}\right)$ of $2.06 \pm 0.20(1 \sigma)$. The remaining eight laboratories had an average $\mu_{\text {geo }}$ of $147.6 \mathrm{~nm} \pm 14.0 \mathrm{~nm}$ and $\sigma_{\text {geo }}=1.80 \pm 0.13$.

Table 1. Aerosol geometric mean diameter $\left(\mu_{\text {geo }}\right)$ and geometric standard deviation $\left(\sigma_{\text {geo }}\right)$.

\begin{tabular}{|c||c|c|}
\hline Lab \# & Mean mobility $\left(\mu_{\text {geo }}, \mathrm{nm}\right)$ & $\sigma_{\text {geo }}$ \\
\hline \hline $2^{\mathrm{a}}$ & - & - \\
4 & 95.8 & 2.19 \\
12 & 96.3 & 2.17 \\
10 & 105.0 & 1.83 \\
3 & 120.6 & 1.61 \\
8 & 131.4 & 1.79 \\
9 & 147.0 & 1.73 \\
5 & 148.0 & 1.87 \\
6 & 152.0 & 1.92 \\
1 & 157.6 & 2.01 \\
7 & 158.0 & 1.79 \\
11 & 163.0 & 1.69 \\
\hline
\end{tabular}

a No mobility data was received from Lab \#2.

Using a differential mobility analyzer (DMA), participants could select a $D_{\mathrm{m}}$ from the aerosol stream. Some participants were also able to select $m_{\mathrm{p}}$ from $D_{\mathrm{m}}$-selected aerosol to report $m_{\mathrm{p}}$ as a function of $D_{\mathrm{m}}$, see Fig. $1 \mathrm{~b}$. Other laboratories measured $m_{\mathrm{p}}$ using a single particle soot photometer (SP2, see triangles in Fig. 1b). The SP2 measures soot incandescence to determine the particle mass and does not measure the particle mass directly. The measured $m_{\mathrm{p}}$ as a function of $D_{\mathrm{m}}$ show that the measured $m_{\mathrm{p}}$ is within a few percent for all $D_{\mathrm{m}}$, with the exception of one laboratory (Lab \#4, see blue circles in Fig. 1b), which also had the lowest 
$\mu_{\text {geo }}$ and $\sigma_{\text {geo }}$, suggesting that $m_{\mathrm{p}}$ and particle morphology may be a function of the particle size distribution between the two $\mu_{\text {geo }}$ groupings.
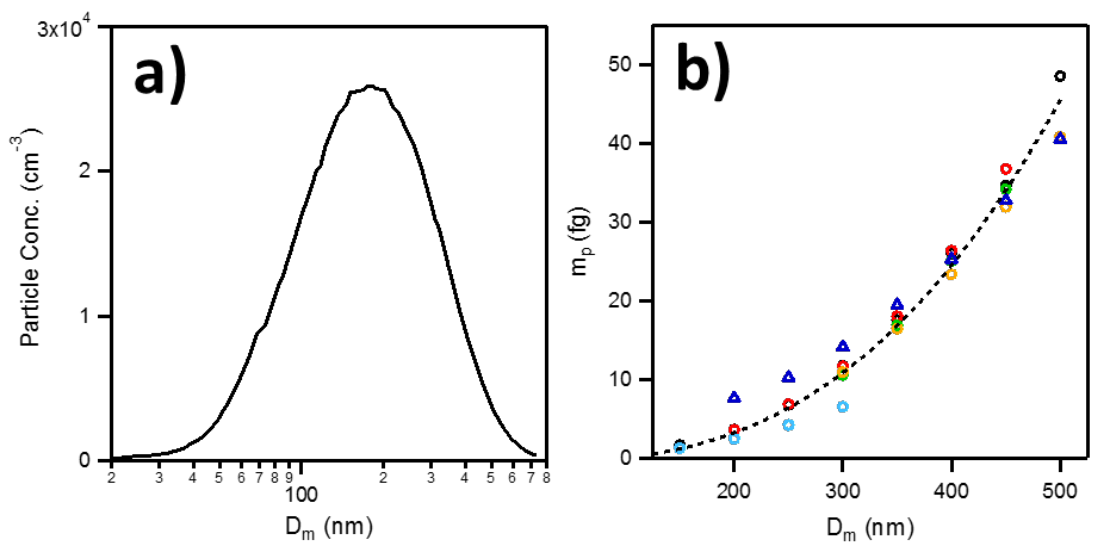

Figure 1. Measured $D_{\mathrm{m}}$ and $m_{\mathrm{p}}$ properties of CB aerosol.

a) Measured aerosol number density $\left(\# \mathrm{~cm}^{-3}\right)$ as a function of mobility diameter, $D_{\mathrm{m}}$ $(\mathrm{nm})$, for the material used in the intercomparison. b) Measured particle mass ( $m_{\mathrm{p}}$, in femtograms, fg) as function of $D_{\mathrm{m}}$ from intercomparison participants. Masses measured using an aerosol mass analyzer are shown by circles and a single particle soot photometer (SP2) are shown by triangles.

The relationship of $m_{\mathrm{p}}$ as a function of $D_{\mathrm{m}}$ can be described using:

$$
m_{\mathrm{p}}=k_{0}\left(\frac{D_{\mathrm{m}}}{250 \mathrm{~nm}}\right)^{D_{\mathrm{f}}}
$$

where $k_{0}=(6.53 \pm 0.45) \times 10^{-15} \mathrm{~g}(\mathrm{fg})$ is the $m_{\mathrm{p}}$ at $250 \mathrm{~nm}$ and $D_{\mathrm{f}}=2.81 \pm 0.12$ is the massmobility scaling exponent. The $D_{\mathrm{f}}$ is related to particle morphology, where $D_{\mathrm{f}}=3$ is consistent with spherical particles $[2,3,11]$.

A technical challenge associated with the measurement of aerosol $C_{\mathrm{Abs}}$ is the isolation of a singular subset of particles from an aerosol distribution. Particle size selection is typically made by selection of a particles electrical mobility $\left(Z_{\mathrm{p}}\right)$ using a DMA. This mobility diameter $\left(D_{\mathrm{m}}\right)$, defined as the diameter of a spherical particle with the same electrical mobility as those being measured, is a function of the particle's electro-motive force (which is a function of charge) and drag force, as described in Eq. 2:

$$
Z_{\mathrm{p}} \propto \frac{q \gamma}{D_{m}}
$$

where $q$ is the net particle charge, and $\gamma$ is the drag-slip correction for non-solid and/or nonspherical particles. Multiple solutions exist for a single $Z_{\mathrm{p}}$ depending upon net charge $(q \geq 1)$ and its drag force (particle morphology), thereby impacting the selection of a single $D_{\mathrm{m}}$ from a particle distribution.

Further particle selection can be achieved using mass-based classification methods that can isolate particles of known $m_{p}$ from $D_{\text {m }}$ selected aerosol. Mass-based selection is typically made using an aerosol particle mass analyzer, or other similar instrument, reducing the 
impact of multiply charged particles from the selected distribution [2, 3]. This is particularly important for aerosol spectroscopy as particles at $q>1$ (larger $D_{\mathrm{m}}$ ) adversely impact the measured $C_{\mathrm{Abs}}$, due to the non-linear relationship of $C_{\mathrm{Abs}}$ with $D_{\mathrm{m}}$. Lastly, selection of particles with known $m_{p}$ facilitates the reporting of $C_{\mathrm{Abs}}$ on a per mass basis, allowing for better quantitative comparability between laboratories and materials, and also enables metrological traceability to the international system of units (SI).

Mass-based measurements facilitated the determination of the presence, quantity and spectral impact of particles bearing multiple charges within a $D_{\mathrm{m}}$ selected distribution, see Table 2 . These results show that more than $20 \%$ of the measured $C_{\mathrm{Abs}}$ for $D_{\mathrm{m}} \leq 350 \mathrm{~nm}$ is derived from multiply charged particles $(q>1)$, as measured from the ratio of reported $C_{\mathrm{Abs}, \mathrm{Dm}}\left(C_{\mathrm{Abs}}\right.$ of $D_{\mathrm{m}}$ selected aerosol) to $C_{\mathrm{Abs}, \mathrm{Dm} \& \mathrm{mp}}\left(C_{\mathrm{Abs}}\right.$ of $D_{\mathrm{m}} \& m_{\mathrm{p}}$ selected aerosol). This observation is also supported by measurements using a single particle soot photometer (SP2), where multiply charged, higher $D_{\mathrm{m}}$ particles account for $>2.5 \%$ of the total number density $(P)$ for $D_{\mathrm{m}} \leq 350 \mathrm{~nm}$. For laboratories with $D_{\mathrm{m}}$-only selection available, CB absorption measurements should be made at $D_{\mathrm{m}} \geq 400 \mathrm{~nm}$ where relative deviations in $C_{\mathrm{Abs}}$ are $\leq 10 \%$ of those using both $D_{\mathrm{m}} \& m_{\mathrm{p}}$ selection.

Table 2. Average ratio of $C_{a b s}$ for $D_{\mathrm{m}}$ and $D_{\mathrm{m}} \& m_{\mathrm{p}}$ selected aerosol and percentage of multiply charged particles $(q>1)$ as determined using an SP2. Uncertainty is $1 \sigma$ of average values

\begin{tabular}{|c||c|c|}
\hline$D_{\mathrm{m}}(\mathrm{nm})$ & $C_{\text {Abs,Dm }} / C_{\text {Abs,Dm\&mp }}$ (5 laboratories) & $\%>1$ using $D_{\text {m-only selection }}$ \\
\hline \hline 150 & $2.50 \pm 0.17$ & - \\
200 & $2.02 \pm 0.09$ & 26.0 \\
250 & $1.62 \pm 0.02$ & 11.6 \\
300 & $1.35 \pm 0.01$ & 5.2 \\
350 & $1.21 \pm 0.01$ & 2.5 \\
400 & $1.10 \pm 0.01$ & 1.2 \\
450 & $1.06 \pm 0.01$ & 0.4 \\
500 & $1.02 \pm 0.01$ & 0.1 \\
\hline
\end{tabular}




\section{Measurement of CB $C_{A b s}$ for $D_{m} \& m_{p}$ selected aerosol}

Five participating laboratories selected particles by $D_{\mathrm{m}} \& m_{\mathrm{p}}$. Two additional laboratories reported $C_{\mathrm{Abs}}$ for $D_{\mathrm{m}}$-selected particles with subsequent analysis to determine $m_{\mathrm{p}}$ and $q=1$ and reported $C_{\mathrm{Abs}}$ on a per mass basis. $C_{\mathrm{Abs}}$ was measured as a function of $D_{\mathrm{m}} \& m_{\mathrm{p}}$ and $\lambda$. Wavelengths reported for $D_{\mathrm{m}} \& m_{\mathrm{p}}$ selected aerosol were $\lambda=(385,405,532,660,785$, and $880) \mathrm{nm}$. All participating laboratories with mass-reporting (7 laboratories) reported $C_{\mathrm{Abs}}$ at $\lambda=(405$ and 532) nm enabling comparability across all laboratories, see Figs 2a and 2b. Reported uncertainties represent $1 \sigma$ from multiple ( $N=3$ to 20) technical replicate measurements as reported by each participating laboratory.
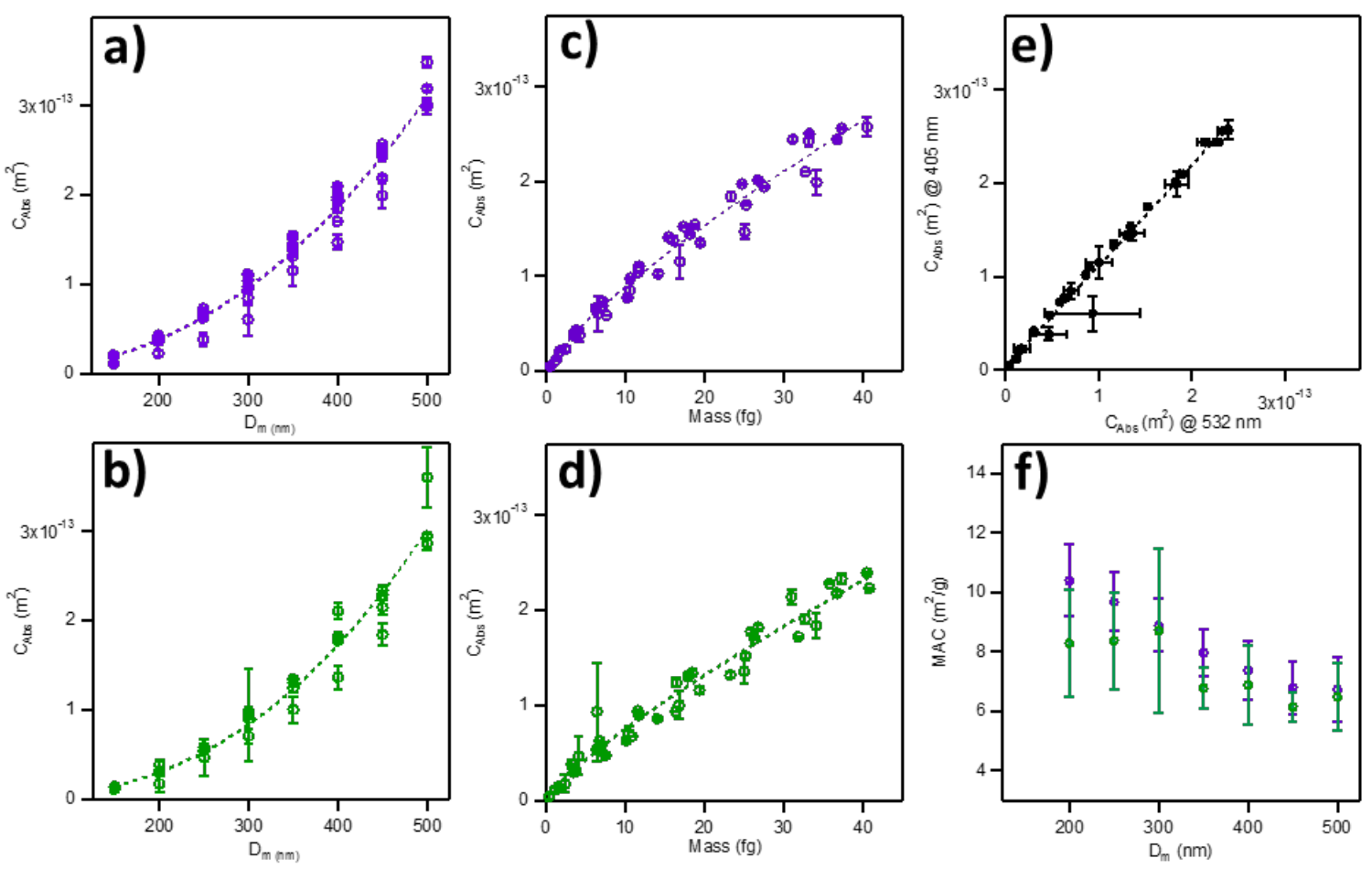

Figure 2. Measured CB properties for $D_{\mathrm{m}} \& m_{\mathrm{p}}$ selected aerosol (7 laboratories).

Measured $C_{\mathrm{Abs}}$ as a function of $D_{\mathrm{m}}$ for $\left(150 \leq D_{\mathrm{m}} \leq 500\right) \mathrm{nm}$ at a) $\lambda=405 \mathrm{~nm}$ and b) $\lambda=532 \mathrm{~nm}$. Measured $C_{\mathrm{Abs}}$ as a function of $m_{\mathrm{p}}$ for $\left(150 \leq D_{\mathrm{m}} \leq 500\right) \mathrm{nm}$ at c) $\lambda=405 \mathrm{~nm}$ and d) $\lambda=532 \mathrm{~nm}$. e) Correlation of $C_{\mathrm{Abs}}$ at $\lambda=(405$ and 532$) \mathrm{nm}$. f) Measured mass absorption coefficients (MAC $=C_{\mathrm{Abs}} / m_{\mathrm{p}}$ ) at $\lambda=405 \mathrm{~nm}$ (violet) and $\lambda=532 \mathrm{~nm}$ (green). Dashed lines in a) through e) represent best fits of the data using a power law (a, b, c, d) or linear (e) relationship.

The relationship between $C_{\mathrm{Abs}}$ as a function of $D_{\mathrm{m}}$ was fit for $\left(150 \leq D_{\mathrm{m}} \leq 500\right) \mathrm{nm}$ using a power law for $\lambda=(405$ and 532) $\mathrm{nm}$.

$$
C_{\mathrm{Abs}}=C_{\mathrm{Abs}, 0}\left(\frac{D_{m}}{250 \mathrm{~nm}}\right)^{D_{\mathrm{Abs}}}
$$

where $C_{\mathrm{Abs}, 0}$ represents the $C_{\mathrm{Abs}}$ at $D_{\mathrm{m}}$ at $250 \mathrm{~nm}$ and $D_{\mathrm{Abs}}$ is the absorption power law scaling exponent. The $C_{\text {Abs }}$ is expected to scale with $m_{\mathrm{p}}$, see Table 3. 
Table 3. Average $C_{\mathrm{Abs}}\left(\mathrm{m}^{2}\right)$ at $D_{\mathrm{m}}=250 \mathrm{~nm}$ and $D_{\mathrm{Abs}}$ at $\lambda=\left(405\right.$ and 532) $\mathrm{nm}^{a}$

\begin{tabular}{|c||c|c|}
\hline (7 laboratories) & $\lambda=405 \mathrm{~nm}$ & $\lambda=532 \mathrm{~nm}$ \\
\hline \hline$C_{\text {Abs }, 0}$ & $6.33 \pm 0.26 \times 10^{-14} \mathrm{~m}^{2}$ & $5.28 \pm 0.41 \times 10^{-14} \mathrm{~m}^{2}$ \\
$D_{\text {Abs }}$ & $2.29 \pm 0.07$ & $2.51 \pm 0.14$ \\
\hline
\end{tabular}

${ }^{a}$ Uncertainties are $1 \sigma$.

Figs. 2c and 2d show the relationship of measured $C_{\mathrm{Abs}}$ and $m_{p}$ for $D_{m} \& m_{p}$ selected aerosol $\lambda=$ (405 and 532). The differences in dependencies of $m_{p}$ and $C_{\mathrm{Abs}}$ with $D_{m}$ are reflected in the power law scaling exponents for each data set resulting in a non-linear correlation between $C_{\mathrm{Abs}}$ and $m_{p}$. Thus, the data in Figs. 2c and 2d ( $C_{\mathrm{Abs}}$ as a function of $\left.m_{p}\right)$ were fit to a power law $\left(C_{\mathrm{Abs}}=A * m_{\mathrm{p}}^{E x p}\right)$ at both $\lambda=(405$ and 532) nm and are shown in Table 4 . These data may be used for evaluation of aerosol PAS performance of CB at each $\lambda$ across this $m_{p}$ range.

Table 4. Power law fit parameters of $C_{\mathrm{Abs}}\left(\mathrm{m}^{2}\right)$ as a function of $m_{\mathrm{p}}$ at $\lambda=(405$ and 532) $\mathrm{nm}$ for $\left(150 \leq D_{\mathrm{m}} \leq 500\right) \mathrm{nm}$ with $D_{m} \& m_{p}$ selected aerosol. ${ }^{a}$

\begin{tabular}{|c||c|c|}
\hline (7 laboratories) & $\lambda=405 \mathrm{~nm}$ & $\lambda=532 \mathrm{~nm}$ \\
\hline \hline$A$ & $1.47 \pm 0.13 \times 10^{-14}$ & $1.14 \pm 0.13 \times 10^{-14}$ \\
Exp & $0.783 \pm 0.027$ & $0.816 \pm 0.034$ \\
\hline
\end{tabular}

${ }^{a}$ Uncertainties are $1 \sigma$.

The measured $C_{\mathrm{Abs}}$ at $\lambda=$ (405 and 532) nm were nearly linearly correlated for each participating laboratory $\left(C_{\mathrm{Abs}, 405 \mathrm{~nm}} / C_{\mathrm{Abs}, 532 \mathrm{~nm}}=1.08 \pm 0.03,1 \sigma\right)$, as shown in Fig. 2e. Participating laboratories also reported the mass absorption coefficient (MAC, $\mathrm{m}^{2} \mathrm{~g}^{-1}$ ), calculated as $M A C=C_{\mathrm{Abs}} / m_{\mathrm{p}} . M A C$ is nearly linear with $m_{\mathrm{p}}$ due to the similar scaling of $m_{\mathrm{p}}$ and $C_{\mathrm{Abs}}$ with $D_{\mathrm{m}}$ for both $\lambda$. The $M A C$ at these $\lambda$ is a function of $D_{\mathrm{m}}$ and is shown in Fig. $2 \mathrm{f}$. The $M A C$ is highest at the lowest measured $D_{\mathrm{m}}(200 \mathrm{~nm})$, likely due to full light penetration through the particle. At higher $D_{\mathrm{m}}$, incident light is attenuated due to the compacted spherical morphology of CB, decreasing the reported $M A C$. For $D_{m}>350 \mathrm{~nm}$ the $M A C$ approaches an asymptotic minimum for both $\lambda$. 
The size dependence of $M A C$ was reported as a function of $\lambda$ and $D_{\mathrm{m}}$ from each participating laboratory. Fig. 3a and 3b show $C_{\mathrm{Abs}}$ and $M A C$ as a function of $\lambda$ for $D_{\mathrm{m}}=250 \mathrm{~nm}$ and $450 \mathrm{~nm}$ CB aerosol, respectively. The reported $C_{\mathrm{Abs}}$ increase with $D_{\mathrm{m}}$ due to the concomitant increase of $m_{\mathrm{p}}$. The reported MAC was dependent on $D_{\mathrm{m}}$ across all $\lambda$, consistent with the observed dependence of MAC as a function of $\lambda$, as shown in Fig $2 \mathrm{f}$.
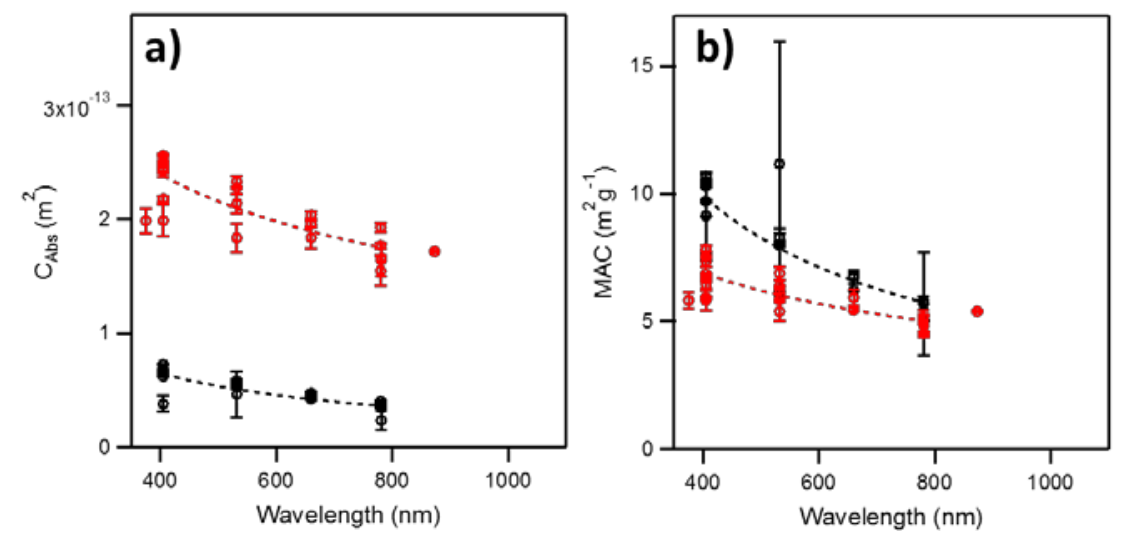

Figure 3. Absorption spectra of $D_{m} \& m_{p}$ selected CB aerosol.

a) $C_{\mathrm{Abs}}$ as a function of $\lambda$ for $D_{\mathrm{m}}=250 \mathrm{~nm}$ (black) and $450 \mathrm{~nm}$ (red) CB aerosol.

b) $M A C$ as a function of $\lambda$ for $D_{\mathrm{m}}=250 \mathrm{~nm}$ (black) and $450 \mathrm{~nm}$ (red) CB aerosol. Uncertainties are $1 \sigma$ of technical replicates. Fits are shown to guide the eye. 


\section{Measurement of CB $C_{A b s}$ for $D_{\mathrm{m}}$-only selected aerosol}

All twelve participating laboratories selected particles by $D_{\mathrm{m}}$-only. $C_{\mathrm{Abs}}$ was measured as a function of $D_{\mathrm{m}}$ and $\lambda$. $C_{\mathrm{Abs}}$ of $D_{\mathrm{m}}$-only selected aerosol was reported as a function of $\lambda$, for $\lambda=(385,405,532,660,785,880$, and 1064$) \mathrm{nm}$. The $C_{\text {Abs }}$ of classified $D_{\mathrm{m}}$ aerosol was reported at $\lambda=\left(405\right.$ and 532) $\mathrm{nm}$ for particles $\left(200 \leq D_{\mathrm{m}} \leq 500\right) \mathrm{nm}$ from eleven participating laboratories. The data was evaluated as a function of $D_{\mathrm{m}}$. Figs $4 \mathrm{a}$ and $4 \mathrm{~b}$ show measured $C_{\mathrm{Abs}}$ as a function of $D_{\mathrm{m}}$ for mobility selected aerosol at $\lambda=405 \mathrm{~nm}$ and $532 \mathrm{~nm}$. Reported uncertainties represent $1 \sigma$ from multiple ( $N=3$ to 20 ) technical replicate measurements as reported from each participating laboratory.
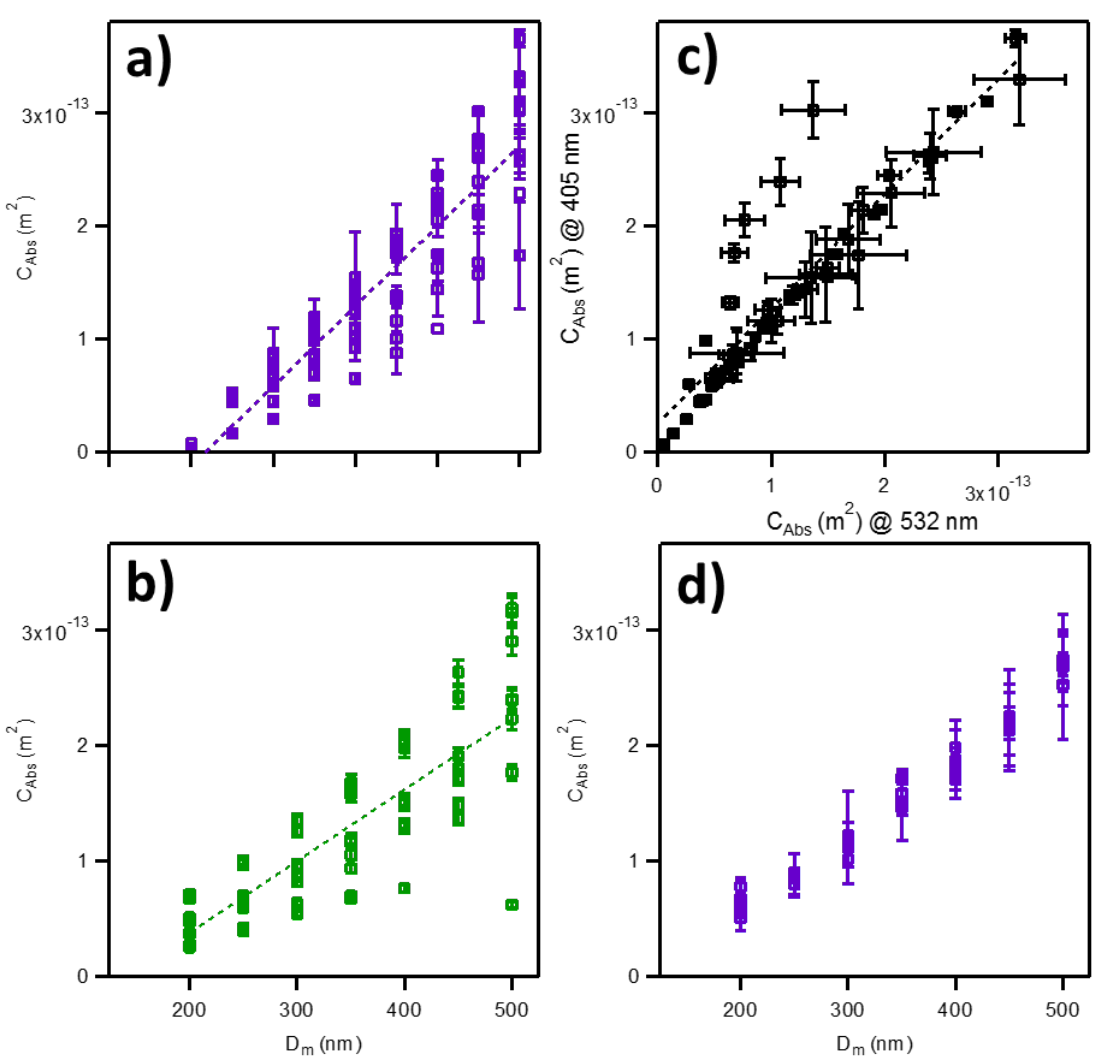

Figure 4. Measured CB properties for $D_{\mathrm{m}}$-only selected aerosol.

Measured $C_{\mathrm{Abs}}$ as a function of $D_{\mathrm{m}}$ for $200 \mathrm{~nm} \leq D_{m} \leq 500 \mathrm{~nm}$ at a) $\lambda=405 \mathrm{~nm}$ and b) $\lambda=532 \mathrm{~nm}$. Dashed lines show linear line of best fit from all participating laboratories. c) Linear correlation of $C_{\mathrm{Abs}}$ at $\lambda=405 \mathrm{~nm}$ and $\lambda=532 \mathrm{~nm}$. d) Corrected measured $C_{\mathrm{Abs}}$ as a function of $D_{\mathrm{m}}$ at $\lambda=405 \mathrm{~nm}$.

When compared to $D_{\mathrm{m}} \& m_{\mathrm{p}}$ selected aerosol, there is significantly more interlaboratory variability in the reported $C_{\mathrm{Abs}}$ at both $\lambda=\left(405\right.$ and 532) $\mathrm{nm}$ for $D_{\mathrm{m}}$-only selected CB, likely due to the inclusion of $q>1$ particles within the output distribution.

With the exception of two laboratories, participants used a single PA spectrometer in the measurement of and reporting $C_{\text {Abs. }}$. In laboratories using a single spectrometer, $\lambda$ was varied by using multiple lasers or other high-powered light sources. This eliminates a source of 
intralaboratory uncertainty that may arise from differences in calibration between two or more spectrometers such as: microphone response and sensitivity, spectrometer frequency response to changes in temperature and/or pressure, and uncertainties between using multiple particle counters used to measure $P$ and/or light power meters used to normalize data. The use of a single photoacoustic spectrometer also reduces the uncertainty in the determination of $\lambda$-dependent spectral features and eliminates sources of uncertainty in the intra-laboratory correlation between multiple $\lambda$. This is illustrated for $D_{\mathrm{m}}$-only selected aerosol where the reported $C_{\mathrm{Abs}}$ at $\lambda=405 \mathrm{~nm}$ and $\lambda=532 \mathrm{~nm}$ are correlated, see Fig 4c,

$C_{\mathrm{Abs}, 405 \mathrm{~nm}} / C_{\mathrm{Abs}, 532 \mathrm{~nm}}=1.01 \pm 0.06(1 \sigma)$, compared to $1.08 \pm 0.03(1 \sigma)$ of $D_{\mathrm{m}} \& m_{\mathrm{p}}$ selected aerosol.

One participating laboratory had a significantly higher $\lambda=405 \mathrm{~nm}$ and $\lambda=532 \mathrm{~nm}$ ratio $(>2)$, atypical of all other reported data from laboratories using only $D_{\mathrm{m}}$-only selection. Importantly, these data were from a laboratory that used multiple spectrometers (one spectrometer at $\lambda=405 \mathrm{~nm}$ and another spectrometer at $\lambda=532 \mathrm{~nm}$ ), highlighting the importance of developing methods of intralaboratory calibration for aerosol PAS measurements.

The reported $C_{\text {Abs }}$ at $\lambda=405 \mathrm{~nm}$ and $532 \mathrm{~nm}$ shown in Fig. 4c shows systematic intralaboratory correlation between measurements. Thus, the reported variability in $C_{\mathrm{Abs}}$ can be corrected as a function of $D_{\mathrm{m}}$ for each laboratory to enable a method of interlaboratory comparability. This is demonstrated in Fig. $4 \mathrm{~d}$ for $\lambda=405 \mathrm{~nm}$, where the reported $C_{\mathrm{Abs}}$ as a function of $D_{\mathrm{m}}$ for each laboratory has been corrected to the linear best fit of the population, as shown in Fig. $4 \mathrm{a}$ at $\lambda=405 \mathrm{~nm}$. Additional fit parameters were calculated at $\lambda=532 \mathrm{~nm}$ and $660 \mathrm{~nm}$, encompassing data from 11 of the 12 reporting laboratories, see Table 5. Importantly, the harmonization is observationally constrained using a linear relationship of $C_{\text {Abs }}$ as a function of $D_{\mathrm{m}}$ (see $D_{\mathrm{m}} \& m_{\mathrm{p}} C_{\text {Abs }}$ power law dependence with $D_{\mathrm{m}}$ shown in Figs. 2a and $2 \mathrm{~b}$ ), and should not be assumed to be quantitative. As discussed above, $D_{\mathrm{m}}$-only selection contains $q>1$ particles for $D_{m}<350 \mathrm{~nm}$, resulting in errors in the reported $C_{\mathrm{Abs}}$.

Table 5. Linear correction fit parameters for $D_{\mathrm{m}}$-only selected $C_{\mathrm{Abs}}$ relative to the population mean.

\begin{tabular}{|c|c|c|c|c|c|c|c|c|c|c|c|c|c|}
\hline$\lambda(\mathrm{nm})$ & Lab \# & 1 & 2 & 3 & 4 & 5 & 6 & 7 & 8 & 9 & 10 & 11 & 12 \\
\hline \multirow[t]{2}{*}{405} & $m^{\mathrm{a}}$ & 2.7 & 1.3 & - & -35 & - & -8.2 & -10.6 & -8.56 & -20.4 & -1.3 & 24.2 & - \\
\hline & $b^{\mathrm{b}}$ & -1.9 & 5.7 & - & 80 & - & -0.5 & -3.3 & 13 & 141 & -10.3 & -43.6 & - \\
\hline \multirow[t]{2}{*}{532} & $m^{a}$ & 1.5 & -2.1 & 32.2 & -30.5 & - & -10.8 & -16.9 & 28.3 & - & - & 16 & - \\
\hline & $b^{b}$ & -3.5 & 10.6 & -51.2 & 72 & - & -0.1 & 12.9 & -42.7 & - & - & -30.4 & - \\
\hline \multirow[t]{2}{*}{660} & $m^{a}$ & - & - & - & -25.7 & - & 4.7 & -5.7 & - & -26.3 & - & 19.8 & -22.2 \\
\hline & $b^{b}$ & - & - & - & 78.4 & - & -20.7 & -8 & - & 43.4 & - & -34.8 & 43.4 \\
\hline
\end{tabular}

$a \quad$ slope $=m \times 10^{-17} \mathrm{~m}^{2} \mathrm{~nm}^{-1}$

$b \quad$ intercept $=b \times 10^{-15} \mathrm{~m}^{2}$

$C_{\text {Abs }}$ for $D_{\mathrm{m}}$-only classified CB were plotted as a function of $\lambda$ to construct absorption spectra and are shown in Fig. 5 for $D_{\mathrm{m}}=250 \mathrm{~nm}$ and $450 \mathrm{~nm}$ for comparison to similar data plotted over the same range of $\lambda$ for $D_{\mathrm{m}} \& m_{\mathrm{p}}$ selected data in Fig 3a. Note the increased intralaboratory uncertainty for $D_{\mathrm{m}}$-only selected aerosol when compared to $D_{\mathrm{m}} \& m_{\mathrm{p}}$ selected data shown in Fig. 3a. 


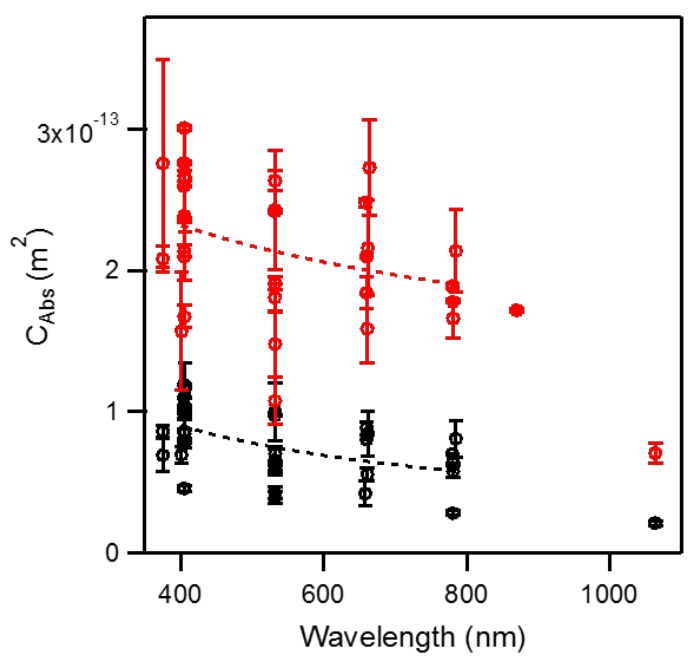

Figure 5. Absorption spectra of $D_{m}$-only selected CB aerosol.

a) $C_{\mathrm{Abs}}$ as a function of $\lambda$ for $D_{\mathrm{m}}=250 \mathrm{~nm}$ (black) and $450 \mathrm{~nm}$ (red) CB aerosol. Uncertainties are $1 \sigma$ of technical replicates. Fits are shown to guide the eye.

\section{Comparison of $D_{\mathrm{m}}$-only and $D_{\mathrm{m}} \& m_{\mathrm{p}}$ selected CB $C_{\mathrm{Abs}}$ measurements}

The measured $C_{\mathrm{Abs}}$ were evaluated by aerosol selection method ( $D_{\mathrm{m}}$-only versus $\left.D_{\mathrm{m}} \& m_{\mathrm{p}}\right)$ at $\lambda=(405,532$, and 785$) \mathrm{nm}$, where there was sufficient data for comparability, for $\left(200 \leq D_{\mathrm{m}} \leq 500\right) \mathrm{nm}$. Table 6 shows the coefficient of variation $(\mathrm{CV}=100 \sigma / \bar{x})$ for each method of selection at $\lambda=(405,532$ and 785$) \mathrm{nm}$ across all intercomparison participants. The CV of $D_{\mathrm{m}}$-only selected CB was (25 to 30 ) \%. Selection of aerosol by $D_{\mathrm{m}} \& m_{\mathrm{p}}$ reduced the $\mathrm{CV}$ by (2 to 3 ) times when compared to the same laboratories using only $D_{\mathrm{m}}$-only selection.

Table 6. CV for $D_{\mathrm{m}}$-only versus $D_{\mathrm{m}} \& m_{\mathrm{p}}$ selected CB for $\lambda=(405,532$, and 660$) \mathrm{nm}$.

\begin{tabular}{|c||c|c|c|}
\hline \multicolumn{1}{|c||}{} & \multicolumn{3}{c|}{$200 \mathrm{~nm} \leq D_{\mathrm{m}} \leq 500 \mathrm{~nm}$} \\
\cline { 2 - 4 } & $\lambda=405 \mathrm{~nm}$ & $\lambda=532 \mathrm{~nm}$ & $\lambda=785 \mathrm{~nm}$ \\
\hline \hline$D_{\mathrm{m}}$-only (12 laboratories) & $25.4 \pm 2.5$ & $30.2 \pm 6.8$ & $24.8 \pm 11.7$ \\
$D_{\mathrm{m}} \& m_{\mathrm{p}}$ (7 laboratories) & $8.3 \pm 3.4$ & $11.3 \pm 8.3$ & $7.1 \pm 6.3$ \\
\cline { 2 - 4 }$C V$ ratio from same 7 labs & $2.8 \pm 0.7$ & $2.1 \pm 0.7$ & $3.6 \pm 2.2$ \\
\hline
\end{tabular}




\section{Interlaboratory comparison of $\mathrm{CB} C_{\mathrm{Abs}}$}

The consistency of each participant's results were evaluated using “z-scores”

$$
z=(x-\bar{x}) / \sigma
$$

where $x$ is a reported value, $\bar{x}$ is the arithmetic mean of all values reported for the same nominal conditions, and $\sigma$ is the standard deviation of these values. These normalized measures of relative performance were calculated for each participant as a function of both $D_{\mathrm{m}}$ and $\lambda$ for $D_{\mathrm{m}}$-only selected aerosol, see Fig. 6 and Table 7 .

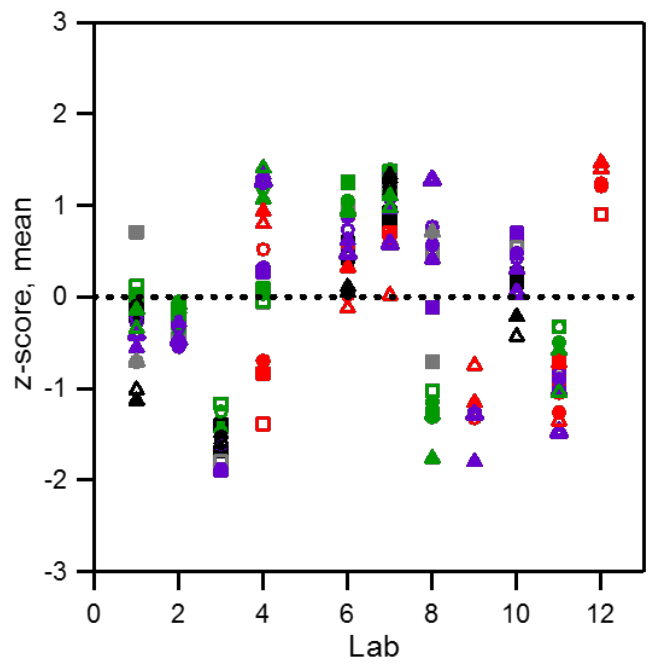

Figure 6. z-scores as a function of $D_{\mathrm{m}}$ for $D_{\mathrm{m}}$-only selected aerosol.

$D_{\mathrm{m}}$ values are indicated by symbol shape: $200 \mathrm{~nm}=$ solid squares, $250 \mathrm{~nm}=$ open squares, $300 \mathrm{~nm}$ = solid circles, $350 \mathrm{~nm}$ = open circles, $400 \mathrm{~nm}=$ solid triangles, and $450 \mathrm{~nm}=$ open triangles. $\lambda$ values are indicated by symbol color: $\lambda=405 \mathrm{~nm}$, $532 \mathrm{~nm}, 660 \mathrm{~nm}$, and $785 \mathrm{~nm}$.

The calculated $z$-scores show that most participating laboratories were systematically biased relative to the reported mean. 
Table 7. Calculated z-score for $D_{m}$ selected aerosol at $\lambda=405 \mathrm{~nm}, 532 \mathrm{~nm}$, and $660 \mathrm{~nm}$ for each participating laboratory.

\begin{tabular}{|c|c|c|c|c|c|c|c|c|c|c|c|c|c|c|c|c|c|c|c|c|c|}
\hline \multirow[b]{2}{*}{$D_{m}$} & \multicolumn{7}{|c|}{$\lambda=405 \mathrm{~nm}$} & \multicolumn{7}{|c|}{$\lambda=532 \mathrm{~nm}$} & \multicolumn{7}{|c|}{$\lambda=660 \mathrm{~nm}$} \\
\hline & 200 & 250 & 300 & 350 & 400 & 450 & 500 & 200 & 250 & 300 & 350 & 400 & 450 & 500 & 200 & 250 & 300 & 350 & 400 & 450 & 500 \\
\hline Lab \# & \multicolumn{21}{|c|}{ Z-score, mean } \\
\hline 1 & -0.08 & -0.13 & -0.28 & -0.23 & -0.56 & -0.40 & 1.25 & 0.02 & 0.13 & -0.05 & 0.03 & -0.14 & -0.35 & 0.92 & - & - & - & - & - & - & - \\
\hline 2 & -0.22 & -0.45 & -0.54 & -0.33 & -0.28 & -0.47 & 1.22 & -0.13 & -0.18 & -0.36 & -0.05 & -0.09 & -0.13 & 0.91 & - & - & - & - & - & - & - \\
\hline 3 & -1.89 & -1.80 & -1.88 & -1.60 & - & - & - & -1.39 & -1.17 & -1.48 & -1.25 & - & - & - & - & - & - & - & - & - & - \\
\hline 4 & 0.28 & -0.05 & 0.32 & 1.23 & 1.33 & 1.26 & 1.95 & 0.09 & -0.05 & 0.03 & 1.19 & 1.07 & 1.41 & 1.37 & -0.84 & -1.39 & -0.70 & 0.52 & 0.93 & 0.80 & 2.66 \\
\hline 5 & - & - & - & - & - & - & - & - & - & - & - & - & - & - & - & - & - & - & - & - & - \\
\hline 6 & 0.96 & 0.96 & 0.88 & 0.73 & 0.62 & 0.48 & 1.58 & 1.26 & 1.25 & 1.05 & 1.04 & 0.93 & 0.95 & 1.22 & 0.91 & 0.50 & 0.08 & 0.02 & 0.32 & -0.12 & 2.10 \\
\hline 7 & 1.37 & 1.24 & 1.36 & 1.09 & 0.97 & 0.58 & 1.70 & 1.13 & 1.38 & 1.39 & 1.30 & 1.11 & 0.98 & 1.38 & 0.82 & 0.71 & 0.67 & 0.59 & 0.62 & 0.02 & 2.40 \\
\hline 8 & -0.12 & 0.47 & 0.57 & 0.77 & 0.41 & 1.27 & 0.36 & -1.27 & -1.02 & -1.15 & -1.31 & -1.77 & -1.28 & -0.13 & - & - & - & - & - & - & - \\
\hline 9 & - & - & - & -1.25 & -1.80 & -1.29 & 1.03 & - & - & - & - & - & - & - & - & - & - & -1.32 & -1.15 & -0.75 & 1.89 \\
\hline 10 & 0.69 & 0.54 & 0.48 & 0.42 & 0.30 & 0.04 & 1.39 & - & - & - & - & - & - & - & - & - & - & - & - & - & - \\
\hline 11 & -0.99 & -0.78 & -0.90 & -0.83 & -1.01 & -1.48 & 0.66 & -0.72 & -0.32 & -0.50 & -0.33 & -0.58 & -1.04 & 0.54 & -0.89 & -0.72 & -1.26 & -1.05 & -0.72 & -1.35 & 1.36 \\
\hline 12 & - & - & - & - & - & - & - & - & - & - & - & - & - & - & - & 0.90 & 1.21 & 1.24 & 1.47 & 1.40 & - \\
\hline
\end{tabular}




\section{Conclusions}

The reported data give guidance to enable quantitative measurements of aerosolized $\mathrm{CB}$ and facilitate spectrometer calibration using either $D_{\mathrm{m}}$-only or $D_{\mathrm{m}} \& m_{\mathrm{p}}$ selection and illustrate the importance of the method used in particle selection for aerosol PAS measurements.

Interlaboratory variability of $C_{\mathrm{Abs}}$ is $7 \%$ to $11 \%$ using $D_{\mathrm{m}} \& m_{\mathrm{p}}$ selection and $25 \%$ to $30 \%$ for particles selected by $D_{\mathrm{m}}$-only.

Despite the reported variability in $C_{\mathrm{Abs}}$ using $D_{\mathrm{m}}$-only selection, the results indicate that quantitative measurements of aerosolized CB are possible for $D_{\mathrm{m}} \geq 400 \mathrm{~nm}$, where differences in reported $C_{\mathrm{Abs}}$ are $\leq 10 \%$ of measurements made with $D_{\mathrm{m}} \& m_{\mathrm{p}}$ selection.

The reported results indicate that PAS measurements using $D_{\mathrm{m}} \& m_{\mathrm{p}}$ selection were able to be collected across the entire $D_{\mathrm{m}}$ range explored in the study $\left(200 \leq D_{\mathrm{m}} \leq 500\right) \mathrm{nm}$ with $<10 \%$ variation between laboratories for $\lambda=405 \mathrm{~nm}$ and $532 \mathrm{~nm}$.

The reported results also indicate that for multiple wavelength measurements should be performed using a single photoacoustic cell to eliminate variation in measurement parameters, if possible. 


\section{References}

[1] IPCC (2013) Climate Change 2013: The Physical Science Basis. Contribution of Working Group I to the Fifth Assessment Report of the Intergovernmental Panel on Climate Change (Cambridge University Press, Cambridge, United Kingdom and New York, NY, USA), Vol. p 1535.

[2] Radney JG, You R, Zachariah MR, Zangmeister CD (2017) Direct In Situ Mass Specific Absorption Spectra of Biomass Burning Particles Generated from Smoldering Hard and Softwoods. Environmental Science and Technology 51(10):5622-5629. https://doi.org/10.1021/acs.est.7b00810

[3] Radney JG , Zangmeister CD (2016) Practical limitations of aerosol separation by a tandem differential mobility analyzer-aerosol particle mass analyzer. Aerosol Science and Technology 50(2):160-172. https://doi.org/10.1080/02786826.2015.1136733

[4] Baumgardner D, Popovicheva O, Allan J, Bernardoni V, Cao J, Cavalli F, Cozic J, Diapouli E, Eleftheriadis K, Genberg PJ, Gonzalez C, Gysel M, John A, Kirchstetter TW, Kuhlbusch TAJ, Laborde M, Lack D, Muller T, Niessner R, Petzold A, Piazzalunga A, Putaud JP, Schwarz J, Sheridan P, Subramanian R, Swietlicki E, Valli G, Vecchi R, Viana M (2012) Soot reference materials for instrument calibration and intercomparisons: a workshop summary with recommendations. Atmospheric Measurement Techniques 5(8):1869-1887. https://doi.org/10.5194/amt-5-1869-2012

[5] Cross ES, Onasch TB, Ahern A, Wrobel W, Slowik JG, Olfert J, Lack DA, Massoli P, Cappa CD, Schwarz JP, Spackman JR, Fahey DW, Sedlacek A, Trimborn A, Jayne JT, Freedman A, Williams LR, Ng NL, Mazzoleni C, Dubey M, Brem B, Kok G, Subramanian R, Freitag S, Clarke A, Thornhill D, Marr LC, Kolb CE, Worsnop DR, Davidovits P (2010) Soot Particle StudiesInstrument Inter-ComparisonProject Overview. Aerosol Science and Technology 44(8):592-611.

https://doi.org/10.1080/02786826.2010.482113

[6] Muller T, Henzing JS, de Leeuw G, Wiedensohler A, Alastuey A, Angelov H, Bizjak M, Coen MC, Engstrom JE, Gruening C, Hillamo R, Hoffer A, Imre K, Ivanow P, Jennings G, Sun JY, Kalivitis N, Karlsson H, Komppula M, Laj P, Li SM, Lunder C, Marinoni A, dos Santos SM, Moerman M, Nowak A, Ogren JA, Petzold A, Pichon JM, Rodriquez S, Sharma S, Sheridan PJ, Teinila K, Tuch T, Viana M, Virkkula A, Weingartner E, Wilhelm R, Wang YQ (2011) Characterization and intercomparison of aerosol absorption photometers: result of two intercomparison workshops. Atmospheric Measurement Techniques 4(2):245-268. https://doi.org/10.5194/amt-4-245-2011

[7] Sheridan PJ, Arnott WP, Ogren JA, Andrews E, Atkinson DB, Covert DS, Moosmüller H, Petzold A, Schmid B, Strawa AW, Varma R, Virkkula A (2005) The Reno Aerosol Optics Study: An Evaluation of Aerosol Absorption Measurement Methods. Aerosol Science and Technology 39(1):1-16. https://doi.org/10.1080/027868290901891

[8] Slowik JG, Cross ES, Han JH, Davidovits P, Onasch TB, Jayne JT, WilliamS LR, Canagaratna MR, Worsnop DR, Chakrabarty RK, Moosmuller H, Arnott WP, Schwarz JP, Gao RS, Fahey DW, Kok GL, Petzold A (2007) An inter-comparison of instruments measuring black carbon content of soot particles. Aerosol Science and Technology 41(3):295-314. https://doi.org/10.1080/02786820701197078 
[9] Bond TC , Bergstrom RW (2006) Light absorption by carbonaceous particles: An investigative review. Aerosol Science and Technology 40(1):27-67.

[10] You R, Radney JG, Zachariah MR, Zangmeister CD (2016) Measured WavelengthDependent Absorption Enhancement of Internally Mixed Black Carbon with Absorbing and Nonabsorbing Materials. Environmental Science\&Technology 50(15):7982-7990. https://doi.org/10.1021/acs.est.6b01473

[11] Zangmeister CD, Radney JG, Dockery LT, Young JT, Ma XF, You RA, Zachariah MR (2014) Packing density of rigid aggregates is independent of scale. Proceedings of the National Academy of Sciences of the United States of America 111(25):9037-9041. https://doi.org/10.1073/pnas.1403768111 


\section{Appendix: Supplemental Materials}

\section{Letter Describing Intercomparison to Potential Contributors}

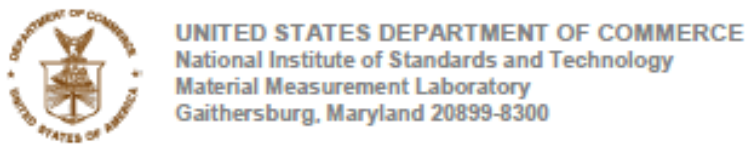

May 11, 2017

The National Institute of Standards and Technology (NIST) is exploring the preparation of an aerosolizable absorbing carbonaceous reference material with well characterized optical properties. An initial aim is to use this material to assess inter-laboratory variability in photoacoustic spectroscopic measurements as determined by the measurement of absorption cross-sections on a particle mobility and/or mass basis. NIST has conducted intercomparisons for over a century. Such intercomparisons assist the scientific community in assessment and guidance of performance and quantitative understanding. To further this goal NIST is organizing an intercomparison from laboratories with published histories of aerosol photoacoustic spectroscopic measurements. NIST is inviting your laboratory for participation.

The sample to be used in the intercomparison is a water soluble black carbon material with absorption across a broad wavelength region (visible to nIR). The particles produced are amenable to aqueous atomization, drying and mobility selection between $150 \mathrm{~nm}$ and $400 \mathrm{~nm}$. Measured optical and experimental data will be collected from each laboratory and recorded in a standardized reporting template. Recorded data will be sent to NIST where it will be used in the intercomparitive study. Data reporting and treatment will be kept anonymous and confidential throughout the study. Wavelength selection, sample drying and mobility/mass selection will be dependent on the technical resources available in each laboratory. It is expected that all participants will measure the absorption cross-section of the material using mobility, and if possible, mass selected particles. Participation in the intercomparison requires the use of an atomization source, sample drying (diffusion drier, etc.), mobility selection and mass selection (if available), photoacoustic spectrometer, and a particle counter. Additional guidance will be provided for participants at a later date. Data will be reported as a per particle cross-section $\left(\mathrm{m}^{2}\right.$ per particle) and/or as a mass specific absorption cross-section ( $\mathrm{m}^{2}$ per gram) for each mobility diameter measured.

Samples will be dispensed to participating laboratories at the beginning of June 2017 and the aim will be to have all data collection completed within 8 weeks (beginning of August 2017) after the sample is received. The full set of anonymous data will be disseminated to each participant laboratory after completion of the intercomparison. We aim to publish the results in a peer reviewed journal with each laboratory participant listed as coauthors.

Thank you for your consideration and hope you can participate,

Chris Zangmeister Ph.D.

Aerosol Metrology Program

National Institute of Standards and Technology 


\section{Cover Letter Distributed to Participants}

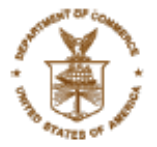

UNITED STATES DEPARTMENT OF COMMERCE

National Institute of Standards and Technology

Material Measurement Laboratory

Gaithersburg, Maryland 20899-8300

June 12,2017

Thank you for participating in the aerosol photoacoustic absorption intercomparison. Its goal is the assessment of quantitative aerosol photoacoustic absorption measurements by established laboratories using a well-characterized material. Aerosol photoacoustic absorption cross-sections will be determined on a mobility and, if possible, per mass basis.

The sample to be used for the intercomparison is packed in a sealed vial included in the envelope located in the shipping box. Also included is a Material Safety Data Sheet (MSDS) of the material. The particles produced are amenable to aqueous atomization, drying and size selection between $150 \mathrm{~nm}$ and $450 \mathrm{~nm}$. Measured optical and experimental data will be collected from each laboratory, recorded in a standardized reporting template that has been sent via email to each participating laboratory.

Each participating laboratory has a published history of aerosol photoacoustic expertise. Thus, it is assumed that, based on prior published experience, each laboratory will utilize its own established best practices in measuring aerosol absorption cross sections. Thus, there is no set procedure, but the following guidelines are provided:

How to use this material. Included are three vials that each contain $0.46 \mathrm{~mL}$ of aqueous solution per vial. A single sample vial should be sufficient for all data collection. However, two additional vials are included, if required. To prepare a sample for use, dilute one vial with $\mathrm{H}_{2} \mathrm{O}$ to $100 \mathrm{~mL}$ total volume. Stirring or sonication is recommended but not required. The solution can be used immediately and is shelf stable at room temperature for over 1 year.

Experiments at NIST conducted using a cross-flow atomizer (e.g. TSI 3076) in conjunction with the prepared solution generates particles with a mean mobility diameter of $\approx 150 \mathrm{~nm}$ with a geometric standard deviation of 1.86. It is recommended that the aerosol stream is dried prior to analysis. It was observed that particle absorption of mass/mobility selected particles are not impacted by the method of particle drying. Examples of drying conditions tested at NIST include combinations of multiple diffusion driers in series, Nafion driers, and a tube furnace at $350^{\circ} \mathrm{C}$ in conjunction with a diffusion dryer.

Elimination of multiply charged particles and measurements to be made. Spectroscopic measurements should be made in a regime where multiply charged particles $(q=+2$, etc.) are minimized or are not present. NIST has undertaken experiments to understand the mobility regime required for elimination of multiple charged particles from the distribution in the absence of mass selection. Extinction measurements of mass distributions of mobility selected particles indicate that using the aerosol generation conditions described above mobility diameters $\geq 350 \mathrm{~nm}$ do not contain $\mathrm{q}=+2$ particles. To ensure measurements minimize the impact of multiple charges, measurements will be made and reported at 350 $\mathrm{nm}, 400 \mathrm{~nm}, 450 \mathrm{~nm}$, and $500 \mathrm{~nm}$ (if possible). In addition, for data comparison, 
measurements will also be made and reported at $<350 \mathrm{~nm}$. Specifically, absorption measurements are to made for mobility diameters of $200 \mathrm{~nm}, 250 \mathrm{~nm}, 300 \mathrm{~nm}, 350 \mathrm{~nm}, 400$ $\mathrm{nm}, 450 \mathrm{~nm}$, and $500 \mathrm{~nm}$ (if possible).

Particle size distribution should be measured by each laboratory and report measured geometric mean and geometric standard deviation.

Importantly, participating laboratories should make absorption measurements at as many wavelengths as at their disposal. This will enable better comparison among participating laboratories.

In additional to mobility selected measurements, and if laboratory resources are present, perform and report measurements for mass selected aerosol (using an APM, CPMA, etc.) at each mobility diameter $(350 \mathrm{~nm}, 400 \mathrm{~nm}$, and $450 \mathrm{~nm})$ and report data as $\mathrm{m}^{2}$ per gram.

Reporting data. Reported data will include:

1) Geometric mean

2) Geometric standard deviation

3) Absorption cross section ( $\mathrm{m}^{2}$ per particle) at each particle mobility ( $200 \mathrm{~nm}-450$ $\mathrm{nm}$ ) and at each available wavelength. Report number of measurements at each particle mobility. Report standard deviation across number of photoacoustic measurements.

4) If measured, in addition to the above, the mass-specific absorption cross section ( $\mathrm{m}^{2}$ per gram) for each mobility/mass combination and wavelength.

Reported data will be anonymous for each participating laboratory. The full set of anonymous data will be disseminated to each participant laboratory after completion of the intercomparison. The final aim is to publish the results in a peer reviewed journal with each laboratory participant listed as co-authors. Please send reported data via email to cdzang@nist.gov by the end of July 2017. Please contact me if additional time is necessary or if you have questions.

Thank you for participating,

Chris Zangmeister Ph.D.

Research Scientist

Materials Measurement Laboratory

National Institute of Standards and Technology

Gaithersburg, MD

301-975-8709

cdzang@nist.gov 


\section{Report to Participants}

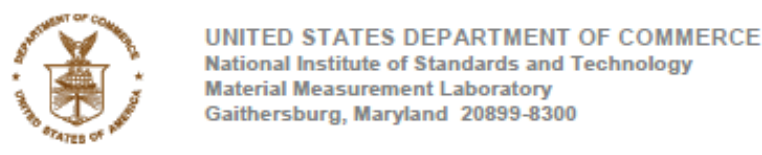

December 21, 2017

Dear Participants,

Thank you all for your efforts in the initial NIST aerosol photoacoustic spectroscopy intercomparison. The goal for the first aerosol photoacoustic intercomparison was participation from 5 to 7 laboratories. The response from the community was much higher. In all, twelve laboratories from six countries agreed to participate and other laboratories subsequently indicated they would like to participate in future intercomparison studies.

All the data from participating laboratories have been received and the data has been plotted as a function of mobility and wavelength for each measurement. Data sufficient for laboratory intercomparison was received at $\lambda=385 \mathrm{~nm}, 404 \mathrm{~nm}, 532 \mathrm{~nm}, 660 \mathrm{~nm}, 785 \mathrm{~nm}$, and $1064 \mathrm{~nm}$ between mobility diameters of $200 \mathrm{~nm}$ and $450 \mathrm{~nm}$. Below is a brief synopsis of the data showing $C_{a b s}\left(\mathrm{~m}^{2}\right)$ as a function of $\lambda$ and particle mobility and $\mathrm{z}$-scores for each laboratory. A more thorough and detailed presentation of the submitted data will be distributed in the next 60 to 90 days and will include $\lambda$ correlations, the impact of multiple charging on the measured distribution and $C_{a b s}$, mass-specific absorption measurements and comparison of mobility vs. mass-selected absorption measurements. In addition to selfand community-evaluation, an additional end goal will be submission of these data to a peer reviewed journal with all participating laboratories listed as co-authors. Input and suggested locations for submission are encouraged. Please do not distribute these data until the study is finalized and the publication is completed.

Thank you for your participation,

Dr. Chris Zangmeister

Research Scientist

National Institute of Standards and Technology

Gaithersburg, MD 20899 USA 
Brief Data Summary:

Figure 1 shows the range in reported $C_{a b s}$ as a function of $\lambda$ at each mobility for all participating laboratories. Typically, the range in $C_{a b s}$ at a $\lambda$ was a factor of 2 to 3 across the laboratories and independent of mobility diameter and $\lambda$. The measured wavelength response was fit using a power law (e.g. $A A E$ normalized at $532 \mathrm{~nm}, k 0$ ).
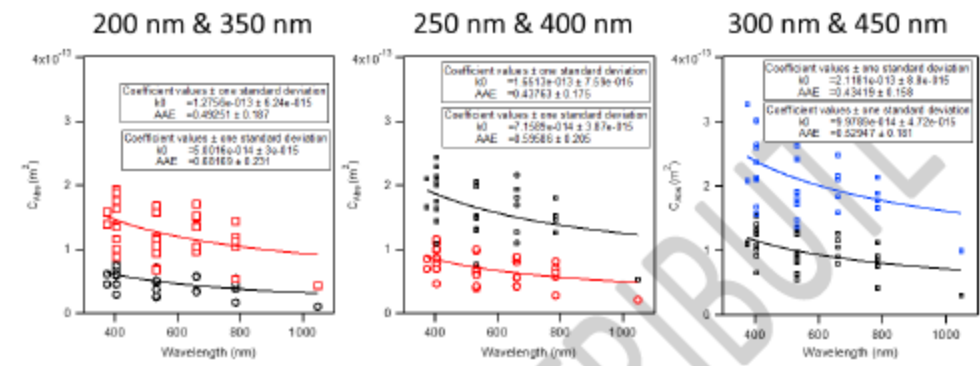

Figure 1. Measured absorption cross-section ( $\left.C_{a b s}\right)$ as a function of wavelength for mobility selected particles. Mobilty shown at top of each plot and separated in $150 \mathrm{~nm}$ to ensure data was well separated in $C_{a b s}$.

Figure 2 shows the same submitted $C_{a b s}$ data plotted for each $\lambda$ as a function of mobility. The line is the linear best fit of the data, $a$ represents the fit slope.

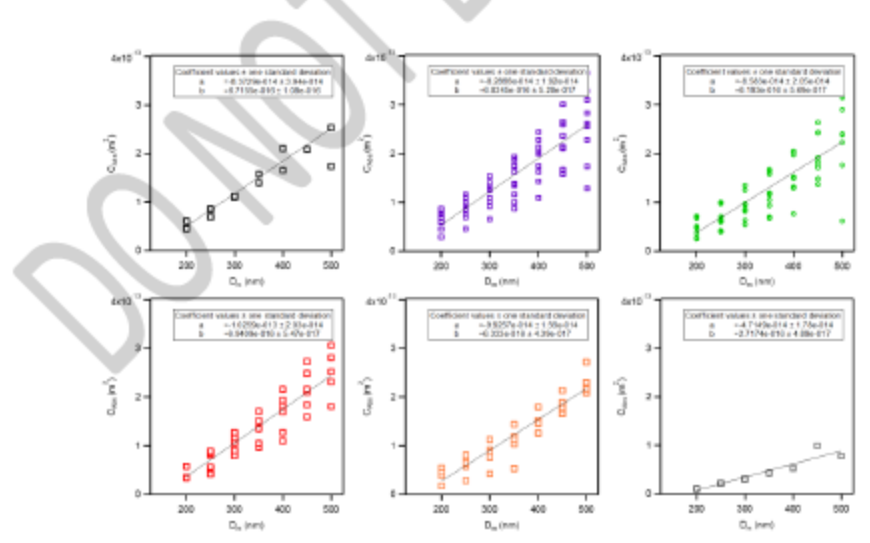

Figure 2. Meaured $C_{a b s}$ as a function of particle mobilty for $385 \mathrm{~nm}$ (top left), $404 \mathrm{~nm}$ (top middle), $532 \mathrm{~nm}$ (top right), $606 \mathrm{~nm}$ (bottom left), $785 \mathrm{~nm}$ (bottom middle), and $1064 \mathrm{~nm}$ (bottom right). 
The most quantitative comparative and evaluative method typically used in laboratory intercomparisons is given by the calculation and reporting of a $z$-score for each participating laboratory. The $z$-score shows the reported data in terms of differences in units of standard deviations $(\sigma)$ from the mean $(\overline{\mathrm{x}})$ for each measurement (mobility and $\lambda$ ) to enable data from independent measurements and laboratories to be quantitatively compared. For example, a $\mathrm{z}$-score of 1 means the reported data is 1 standard deviation higher than the population mean for that mobility and $\lambda$. Z-scores were determined for each laboratory at each mobility for $\lambda=404 \mathrm{~nm}, 532 \mathrm{~nm}, 660 \mathrm{~nm}$, and $785 \mathrm{~nm}$, as defined by

$$
\mathrm{Z}=\frac{c_{A b s}(\lambda, \mathrm{mm})-\overline{\mathrm{x}}, C_{\text {Abs }}(\lambda, \mathrm{nm})}{\sigma(\lambda, \mathrm{nm})},
$$

where $\overline{\mathrm{x}}$ and $\sigma=$ mean and standard deviation at a mobility and wavelength, respectively. The laboratory number in Figure 3 is random and is included for each participant laboratory anonymously in the email sent with this summary.

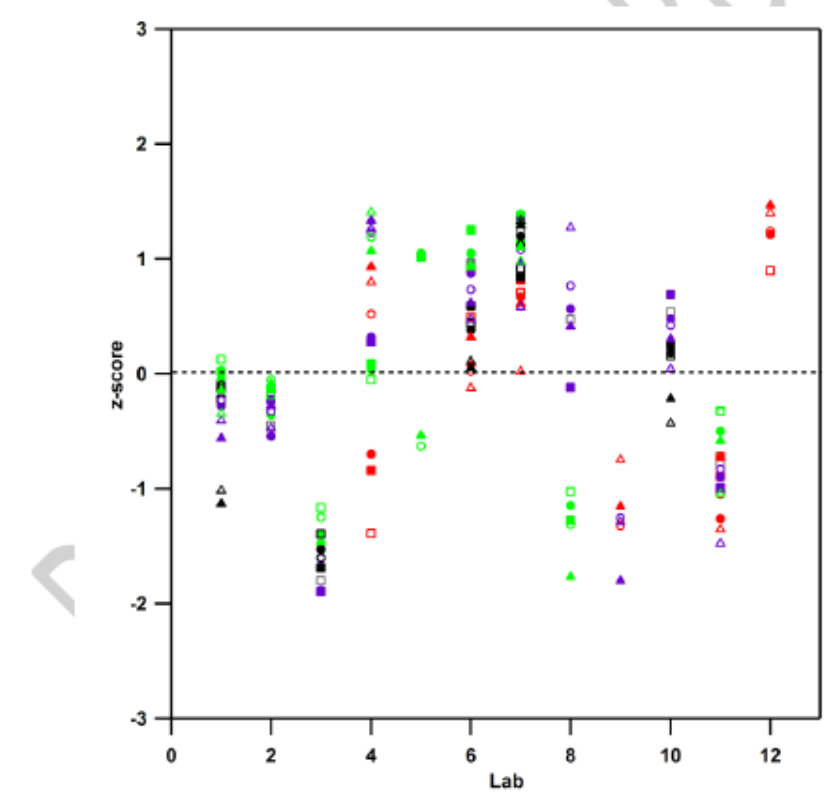

Figure 3. $z$-score for each reporting laboratory as a function of mobility $(200 \mathrm{~nm}=$ solid squares, $250 \mathrm{~nm}=$ open squares, $300 \mathrm{~nm}=$ solid circles, $350 \mathrm{~nm}=$ open circles, $400 \mathrm{~nm}=$ solid triangles, $450 \mathrm{~nm}=$ open triangles) and wavelength $(\lambda=404 \mathrm{~nm}, 532 \mathrm{~nm}, 660 \mathrm{~nm}$, $785 \mathrm{~nm}$ ). 